\title{
O ENEM, nossa responsabilidade como professores e duas tentativas de contribuir com a realidade em que estamos inseridos
}

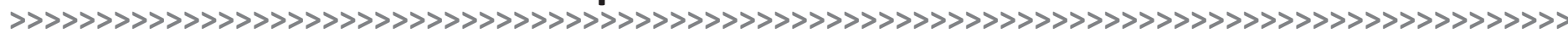

Daniela Favero Netto* Paulo Coimbra Guedes*

\begin{abstract}
Resumo:
A pesquisa realizada estuda práticas cujos objetivos são contribuir com o aprimoramento da produção escrita de alunos da Educação Básica, com o desenvolvimento da capacidade argumentativa em texto oral e escrito; e, ainda, levá-los a pensar, discutir, problematizar, estabelecer relações e a propor soluções para questões da sua realidade e do mundo, o que contribui, inclusive, com sua boa colocação no ENEM. Uma das práticas corresponde à realização de debate e à subsequente produção textual escrita; a outra, ao estudo de três obras de Shakespeare feito por dez alunos do Ensino Médio e à subsequente realização de um ensaio curto. $O$ estudo sugere que utilizar diferentes recursos de pesquisa, estabelecer relações com conhecimentos prévios e, principalmente, variar práticas, criando-se possibilidades que ultrapassam o currículo regular, são recursos que corroboram com o sucesso de atividades que envolvem adolescentes.
\end{abstract}

\section{Palavras-chave:}

Práticas de sala de aula. Argumentação. ENEM.

\begin{abstract}
:
This research analyzes practices whose objectives are to contribute to the improvement of elementary and high school students' writing and to the development of their argumentative capacity both orally and in written texts. It also analyzes the effectiveness of inducing students to think about, discuss, problematize, and establish relationships with and propose solutions to problems related to their reality and the world. These aforementioned factors contributed to the achievement of positive results in the ENEM examination. One of the practices was the realization of a debate and a subsequent written text production. Another was the study of three Shakespearean plays carried out by ten high school students after which they wrote a short essay concerning the study. The results suggest that through using different research resources, establishing relationships with previous knowledge and, in particular, varying activities, one can create possibilities that go beyond the regular curriculum. These practices corroborated to the success of activities involving teenagers.
\end{abstract}

\section{Keywords:}

Classroom practices. Argumentation. ENEM.
* > Doutoranda em Linguística Aplicada (UFRGS) e Professora de Língua Portuguesa do Colégio de Aplicação da UFRGS. E-mail: d.faveronetto@gmail.com.

** > Doutor em Linguística e Letras e Professor do Programa de Pós-Graduação em Letras da UFRGS. E-mail: paulocoimbraguedes@hotmail.com. 


\section{Introdução}

Os resultados do ENEM apontam que há diferenças entre as médias de escolas públicas e de particulares; evidentemente, desconsideram-se, aqui, as escolas públicas militares, as quais apresentam médias similares ou maiores do que as das particulares. Esses dados são mais interessantes para quem não vivencia as diferentes realidades, afinal, quem teve a oportunidade de conhecer as duas não se espanta com os resultados da prova. Sabe-se que atualmente o ENEM tem caráter de concurso, já que o bom desempenho na prova pode garantir uma vaga na universidade; e não há universidade para todos.

A função do professor é oferecer ao aluno subsídios para ir além da escola; que fora dela ele consiga dialogar com o mundo que o cerca e que, acima de tudo, possa agir para transformar esse mundo conforme suas convicções. Se esse aluno quer continuar seus estudos, o professor não pode deixar de contribuir com sua boa colocação no ENEM. Assim, ele deve propor aos alunos atividades que:

1. auxiliem no aprendizado de conteúdos de que necessitam para construir conhecimentos que possam utilizar para transformar a realidade que os cerca;

2. contribuam com seu desempenho no ENEM;

3. estimulem o interesse em aprender.

Pensando nesses objetivos, no ano de 2012, realizaram-se dois trabalhos em que os alunos puderam: aprimorar sua produção escrita; desenvolver a argumentação em texto oral e escrito; pensar, discutir, problematizar, estabelecer relações e propor soluções para questões da realidade deles e do mundo. Na próxima seção, serão descritos e comentados esses trabalhos.

\section{Apresentação e análise de duas práticas de sala de aula}

1 > Apesar de a pesquisa correspondente ao pré-requisito exigido para cumprimento do estágio probatório ter sido concluída, optou-se por dar continuidade aos estudos em 2013, desta vez com o segundo ano do Ensino Médio, pois a prática realizada em 2012 mostrou-se eficaz. Espera-se obter novos direcionamentos, desta vez com análises de produções elaboradas por alunos frequentantes do Ensino Médio.

$2>$ Coordenada pela professora Daniela Favero Netto.

$3>0$ Departamento de Comunicação é formado por duas áreas: a área de Língua Portuguesa e Literatura e a área de Línguas Estrangeiras.

$\mathrm{Na}$ apresentação da primeira prática - a qual se realizou como parte de uma pesquisa (encerrada em 2013 $3^{1}$ intitulada $O$ gênero debate a serviço da capacidade de análise crítica, da autonomia e do posicionamento efica $z^{2}$-, será evidenciada sua relação com alguns estudos, salientando-se o que foi eficaz e o que precisa ser repensado.

A prática corresponde à execução do projeto, pré-requisito para a conclusão do estágio probatório como professora do Departamento de Comunicação ${ }^{3}$ do Colégio de Aplicação da UFRGS, e teve início em março de 2012. Ao longo do primeiro semestre, os alunos tiveram a oportunidade de executar as três fases previstas: o estudo inicial, o estudo para aprofundamento e o estudo para revisão, cujo detalhamento não será feito aqui.

O primeiro debate teve como tema a seguinte afirmação: "É legítimo haver formatura da oitava série do CAp-UFRGS em 2012." A escolha desse assunto deu-se em razão de os alunos envolvidos no projeto serem frequentantes da oitava série e, principalmente, por terem, no início do ano, elaborado um abaixo-assinado solicitando à Direção que a cerimônia de formatura do Ensino Fundamental pudesse ser realizada, celebração que não pertence mais ao calendário escolar há cerca de quatro anos em razão de problemas disciplinares ocorridos na última cerimônia de formatura de oitava série realizada na escola. Sendo um tema de interesse dos alunos, imaginou-se que poderiam realizar um trabalho com mais afinco, o que permitiria que o desempenho dos alunos fosse mais fiel ao que se espera de um debate oral, ou seja, foi uma escolha proposital, para que não executassem o trabalho como um simples cumprimento de tarefa, o que prejudicaria o alcance dos objetivos planejados para o projeto. 
De fato, a escolha do tema foi um sucesso à medida que o debate tornou-se um evento que envolvia a conquista de um objetivo por meio do convencimento não só de todos os alunos, mas também da Direção e dos professores sobre a legitimidade da cerimônia.

Todas as etapas que envolviam a elaboração dos argumentos, bem como da execução do debate foram muito produtivas. Inicialmente, após o sorteio dos integrantes dos grupos da afirmativa e da negativa ${ }^{4}$, houve certa frustração, pois o grupo da negativa sentia-se já derrotado, afinal, nem eles mesmos se convenciam do que deveriam defender. Entretanto, no decorrer do processo de pesquisa de argumentos, alguns alunos do grupo da negativa que tinham, de início, opinião contrária à que deveriam defender, mudaram de opinião, convencendo-se de que a cerimônia de formatura seria irrelevante. E, após a realização do primeiro debate interno (entre grupos de uma mesma turma), inclusive alunos do grupo da afirmativa acabaram mudando de opinião, embora soubessem do dever de defender a tese de seu grupo. Em uma das turmas, foi vitorioso o grupo da afirmativa; na outra, o da negativa, o que facilitou a organização do debate final, pois uma turma defenderia a legitimidade da cerimônia, e a outra, a ilegitimidade.

A turma vencedora foi a que defendeu a ilegitimidade da cerimônia. Não houve discussão acerca do resultado em nenhum momento, porque, como os debates foram filmados, os próprios alunos identificaram muitas de suas falhas e de seus acertos: as melhores defesas de argumentos, a postura mais adequada, a organização mais eficaz das falas (constatações feitas durante o estudo para revisão).

A tarefa subsequente foi a elaboração de um texto de opinião sobre o mesmo assunto. Diferentemente da situação de debate, estariam livres para defender uma posição ou outra, pois já não pertenciam a um dos dois grupos, isto é, a intenção era que o texto expusesse a opinião individual do aluno acerca da legitimidade ou não da realização da cerimônia de formatura da oitava série no Colégio de Aplicação em 2012. O objetivo era escrever um texto para ser publicado no $b \log ^{5}$ especialmente criado para tratar de assuntos referentes ao projeto. Foram apresentados exemplos de texto de opinião, os quais foram estudados com relação às suas peculiaridades, especialmente no que atine à diferença de registro com relação ao texto oral. O resultado foi extremamente positivo; foram feitas relações de aproximação e afastamento referentes às características do debate (oral) e do texto de opinião, escrito para se publicar no blog. Tais relações dizem respeito especialmente às escolhas dos argumentos e à maneira mais adequada de apresentá-los e relacioná-los, o que foi possível aperfeiçoar durante o processo de reescrita do texto.

O segundo tema objeto de debate foi a famosa frase alusiva ao livro $O$ príncipe, de Maquiavel (1513): “Os fins justificam os meios”. A escolha desse tema foi ao encontro de uma necessidade de discussão histórica, proposta pelo professor de História. Entretanto, a orientação dada foi a de que os alunos não precisariam lançar mão unicamente de argumentos com base em fatos históricos.

Para dar início ao processo de pesquisa, os alunos assistiram ao filme Um ato de coragem $^{6}$ como atividade disparadora. Porém, com a greve de professores das Instituições Federais de Ensino, o projeto foi interrompido na fase de estudo para aprofundamento desse último tema. A continuidade do trabalho se deu após o fim da greve, quando teve início o segundo semestre do ano. A expectativa era que houvesse uma diferença motivacional por parte dos estudantes, já que o tema referente à formatura teve uma discussão acalorada, certamente em razão de seu interesse pelo assunto. Todavia, para tentar resgatar a aproximação com o tema percebida no primeiro debate, foram apresentados textos referentes à greve como material de apoio.

O segundo debate não teve o mesmo sucesso nem em envolvimento, nem, consequentemente, em resultados. Os alunos acabaram forjando uma postura formal, prejudicando o desempenho argumentativo, muito provavelmente por seguirem minhas
$4>0$ grupo da afirmativa foi composto por alunos que deveriam se posicionar a favor da realização da formatura, e o grupo da negativa, por alunos que deveriam se posicionar contra a sua realização.

5 > Disponível em: http://pixel80.tumblr. com

6 > Sinopse: John Q. Archibald (Denzel Washington) é um homem comum, que trabalha em uma fábrica e vive feliz com sua esposa Denise (Kimberly Elise) e seu filho Michael (Daniel E. Smith). Até que Michael fica gravemente doente, necessitando com urgência de um transplante de coração para sobreviver. Sem ter condições de pagar pela operação e com o plano de saúde de sua família não cobrindo tais gastos, John Q. se vê então numa luta contra o tempo pela sobrevivência de seu filho. Em uma atitude desesperada, ele então decide tomar como refém todo o setor de emergência de um hospital, passando a discutir uma solução para o caso com um negociador da polícia (Robert Duvall) e com um impaciente chefe de polícia (Ray Liotta), que deseja encerrar o caso o mais rapidamente possível. (Disponível em: http://www.adorocinema.com/filmes/filme-28494/. Acesso em sete de agosto de 2012). 
7 > Minha intenção ao fazer essa solicitação era que evitassem o uso de gírias de uma conversa de bar e determinadas formas de tratamento que utilizam (afinal, seria uma discussão travada entre amigos, colegas que se veem diariamente), ou seja, tratava-se de um trabalho de sala de aula, o que pedia uma linguagem apropriada ao contexto. Meu erro foi acreditar que houvesse a necessidade de fazer tal solicitação. Obviamente, em se tratando de uma atividade escolar, eles não lançariam mão de gírias. Ao pedir "evitem a coloquialidade da língua falada", incorri no erro já apontado por alguns autores: usar o termo coloquial como equivalente à informal e, ainda, o que é pior, induzi-os a pensar que a formalidade está para a escrita e a informalidade está para a fala, quando, na verdade, há outros elementos verbais e não verbais que contribuirão com uma maior ou menor formalidade numa situação de comunicação.

$8>$ Os únicos textos que apresentaram argumentação consistente e que resultaram numa leitura construtiva foram os que versaram sobre a greve, ou seja, os alunos que escolheram um assunto que Ihes parecia interessante, saíram-se bem.

9 > Na concepção de Bakhtin (1992, p. 293), "a unidade real da comunicação verbal".

10 > Nesse caso, a autora se apropriou do discurso do diretor - Trecho 1 - com a intenção de contrapor esse discurso por meio do exemplo utilizado, referente à escola onde sua mãe trabalha, deixando claro o que é posicionamento dela e o que é posicionamento do outro. orientações, pois solicitei que tentassem evitar coloquialidades da língua falada ${ }^{7}$. Com a comparação entre os dois debates, foi possível tecer as seguintes considerações, as quais apontam mudanças no projeto:

a) Um assunto sobre o qual eles não têm interesse não funciona como mote para discussão, pois constituirá cumprimento de tarefa, sem necessariamente resultar num processo de aprendizado ${ }^{8}$. Tentar induzi-los ao interesse em algo de maneira artificial não é produtivo.

b) Exigir um roteiro para o texto falado é importante, mas solicitar a formalidade linguística de um texto de opinião escrito em uma manifestação oral não funciona.

Ao longo do ano de 2012, os alunos das turmas 81 e 82 se apresentaram como sujeitos de suas falas e de seus textos escritos, bem como reconheceram o discurso do outro à medida que as alternâncias dialógicas se evidenciaram no decorrer dos debates e de suas produções textuais, ou seja, houve marcas expressas do que era enunciado ${ }^{9}$ próprio e enunciado do outro. Por vezes, iniciaram sua fala da seguinte maneira, retomando as falas de colegas:

No bloco anterior, a minha colega afirmou que ...

No grupo da negativa, os quatro debatedores falaram que...

Eu concordo com minha colega debatedora...

Tu citou o exemplo do presidente Lula...

De acordo com o que o L. falou...

Em suas produções textuais escritas, também fizeram referência às falas de colegas pronunciadas nos debates, o que pode ser reconhecido no trecho do texto de uma aluna, exemplificado a seguir:

\section{Trecho 1}

No colégio em que nós estamos, há uma estrutura ótima que permite a realização de um evento como uma formatura. O único motivo ao qual o diretor e o grupo da negativa apegaram-se é que há três, melhor dizendo, quatro anos outra oitava série fez um grande evento e houve muita confusão.

Ao referirem-se às falas dos colegas, nos exemplos de debate oral, e às falas do diretor e de um dos grupos de debate, no texto escrito, reconhecem-se como sujeitos do discurso, bem como demarcam uma fronteira entre os enunciados. Estabelece-se, assim, o que Bakhtin denomina de "elo de comunicação verbal” (BAKHTIN, 1992, p. 320), o que pode ser ilustrado pelo parágrafo abaixo, em que a autora da produção escrita evidencia um discurso seu, para contrariar a posição do diretor $(\text { Trecho } 1)^{10}$ :

Trecho 2

Minha mãe é professora de escola pública municipal, escola Mário Quintana. $\mathrm{Na}$ escola dela, sim, há formatura. Mesmo com alunos que têm péssimas condições financeiras e uma escola com estrutura que não há como comparar com a do nosso colégio.

Pode-se, ainda, analisar outros aspectos interessantes que se reconhecem nos exemplos acima. Quais sejam: primeiramente, numa situação de debate oral, é muito provável que a referência ao motivo dado pelo diretor e pelo grupo da negativa (Trecho 1) fosse feita de outra forma; ou seja, a contextualização, o direcionamento do discurso da autora do texto se daria de forma mais imediata; ela diria, por exemplo: com relação ao seu argumento, penso que..., discordo do seu argumento, porque..., em razão da situação dialógica própria de um debate oral, em que os debatedores estariam frente a frente. Ainda, analisando-se do ponto de vista da expressão do enunciador, a intenção demarcada pelo tom de um texto oral se dá de forma diferente, evidentemente, do texto escrito. 
Ao reproduzir-se um enunciado, a demarcação da apropriação do discurso do outro se evidencia. É quando reconhecemos o que Bakhtin denomina de "tonalidade dialógica”. Segundo o autor,

[...] as tonalidades dialógicas preenchem um enunciado e devemos levá-las em conta se quisermos compreender até o fim o estilo do enunciado. Pois nosso próprio pensamento - no âmbito da filosofia, das ciências, das artes - nasce e forma-se em interação e em luta com o pensamento alheio, o que não pode deixar de refletir nas formas de expressão verbal do nosso pensamento. (BAKHTIN, 1992, p. 317).

Para ilustrar: o diretor e o grupo da negativa provavelmente não usariam a palavra "único" (Trecho 1) para qualificar o motivo pelo qual não concordam com a cerimônia de formatura, especialmente com o sentido atribuído pela autora do texto escrito, que, por sua vez, defende a legitimidade da cerimônia de formatura.

É interessante destacar, também, a frase que dá início ao texto da aluna: “Trecho 3 - "Na minha opinião, deve ser legítimo haver formatura na oitava série."

Essa frase evidencia uma resposta a uma pergunta, ou seja, a autora escreve seu texto para alguém que conhece o assunto sobre o qual discorre. Entretanto, trata-se do início de um texto para cuja produção houve uma orientação prévia, na qual houve apresentação de diversos textos de opinião para exemplificação. Houve, inclusive, exemplificação de situações similares, em que o autor falha ao não reconhecer o texto como uma produção que poderá ser lida por qualquer pessoa (ou seja, inclusive para um leitor que desconhece a realização do debate e, especialmente, a proposta sugerida). A orientação para que se fizesse um texto para ser lido por qualquer pessoa era sempre reforçada à medida que constantemente os alunos eram lembrados de que sua produção poderia vir a ser publicada no blog do projeto, ou seja, que poderia ser lida por qualquer um que acessasse o blog.

Relacionando o Trecho 3 com reflexões de Bakhtin acerca de elementos referentes ao enunciado, poder-se-ia afirmar a ocorrência dos seguintes eventos: a "compreensão responsiva" e a influência de "gênero primário" sobre uma produção textual de "gênero secundário".

Os debates, nos moldes em que o projeto em estudo se propõe a realizá-los, embora se caracterizem como um gênero oral, seguem uma estrutura pré-formatada, ou seja, se constroem como textos previamente estruturados, pensados e repensados antes de serem proferidos, contrariando a espontaneidade da fala.

Bakhtin classifica os gêneros da seguinte maneira: primários (simples) e secundários (complexos). Conforme o autor,

[...] os gêneros secundários do discurso - o romance, o teatro, o discurso científico, o discurso ideológico, etc. - aparecem em circunstâncias de uma comunicação cultural, mais complexa e relativamente mais evoluída, principalmente escrita: artística, científica, sociopolítica. Durante o processo de sua formação, esses gêneros secundários absorvem e transmutam os gêneros primários (simples) de todas as espécies, que se constituíram em circunstâncias de uma constituição verbal espontânea. Os gêneros primários, ao se tornarem componentes dos gêneros secundários, transformam-se dentro destes e adquirem uma característica particular: perdem sua relação imediata com a realidade existente e com a realidade dos enunciados alheios. (BAKHTIN, 1992, p. 281).

O enfoque deste estudo é um gênero secundário, pois os textos se realizam num contexto de produção mais complexo; afinal, as falas não são espontâneas, porque cada debatedor tem um tempo determinado tanto para iniciar como para concluir sua exposição. Ademais, como dito, antes de serem proferidos, os textos falados nos debates muitas vezes foram previamente redigidos para então serem apresentados. 
Como foi citado, o gênero primário, embora perpasse o gênero secundário (nesse caso o debate), perde a relação imediata com os enunciados alheios. No exemplo que segue, que corresponde à fala inicial de uma debatedora, é possível analisar-se esse fato: "Não, não é legitimo haver cerimônia de formatura no Colégio de Aplicação...”

O enunciador usa uma estrutura de resposta para uma pergunta que não aconteceu. Na verdade, trata-se de uma materialização da compreensão responsiva. A compreensão responsiva, nas palavras de Bakhtin, “[...] nada mais é senão a fase inicial e preparatória para uma resposta (seja qual for a forma de sua realização)” (BAKTHIN, 1992, p. 291). Nesse caso, o que houve foi a manifestação de um contradiscurso materializado em forma de resposta oral a um enunciado anteriormente proferido não em forma de pergunta, mas em forma de um argumento que defendia a posição contrária à desse enunciador. Pode-se afirmar que a opção pela estrutura de resposta deu-se em razão da tonalidade dialógica dada pelo enunciador (a debatedora), que quis enfatizar a posição contrária à do grupo oponente.

Assim, a espontaneidade, o imediatismo característicos dos gêneros primários evidentemente não podem ser ilustrados pelo gênero debate, um gênero secundário, ao menos à maneira que ele se realiza no projeto em andamento; no entanto, os gêneros primários podem estar a serviço do gênero secundário, como visto, inclusive marcando tonalidades dialógicas.

Outro exemplo ocorre quando uma debatedora faz uma indagação que não receberá uma resposta imediata, como no seguinte caso: "Lembra que ano passado teve aquele concurso aqui na escola? Pois é, ...”

Trata-se de uma pergunta retórica, que poderia ser transformada em uma afirmação: Vocês sabem que no ano passado houve um concurso aqui na escola... A debatedora, na verdade, utilizou-se de um exemplo conhecido do público a que se dirigia com a intenção de contextualizar o assunto de sua fala (os ouvintes recordaram-se, obviamente, do fato que ela retomou), a fim de embasar seu argumento, apresentado posteriormente. Assim, conforme Bakhtin,

[...] o enunciado está ligado não só aos elos que o precedem mas também aos que lhe sucedem na cadeia da comunicação verbal. No momento em que o enunciado está sendo elaborado, os elos, claro, ainda não existem. Mas o enunciado, desde o início, elabora-se em função da eventual reação-resposta, a qual é o objetivo preciso de sua elaboração. [...] Os outros, para os quais meu pensamento se torna, pela primeira vez, um pensamento real (e, com isso, real para mim), não são ouvintes passivos, mas participantes ativos da comunicação verbal. Logo de início, o locutor espera deles uma resposta, uma compreensão responsiva ativa. Todo enunciado se elabora como que para ir ao encontro dessa resposta. (BAKHTIN, 1992, p. 320).

Nesse sentido, pode-se retomar o Trecho 3, já exemplificado e, aqui, novamente citado: "Na minha opinião, deve ser legítimo haver formatura na oitava série."

O destinatário do texto, para ela, conhece a proposta de redação, afinal, ela usa uma estrutura de resposta ao iniciar o texto, como se alguém lhe estivesse perguntando sobre sua opinião acerca da realização da cerimônia de formatura. Além disso, a autora presume que o leitor conhece o fato de ter ocorrido um debate sobre o assunto de que trata o texto, o que fica evidente no Trecho 1 (exemplificado anteriormente).

Sobre o destinatário, Bakhtin assevera que ele

[...] pode ser o parceiro e interlocutor direto do diálogo na vida cotidiana, pode ser o conjunto diferenciado de especialistas em alguma área especializada da comunicação cultural, pode ser o auditório diferenciado de especialistas em alguma área especializada da comunicação cultural, pode ser o auditório diferenciado dos contemporâneos, dos partidários, dos adversários e inimigos, dos subalternos, dos chefes, dos inferiores, dos superiores, dos próximos, dos estranhos, etc.; pode até ser, de modo absoluta- 
mente indeterminado, o outro não concretizado [...]. Essas formas e concepções do destinatário se determinam pela área da atividade humana e da vida cotidiana a que se reporta um dado enunciado. (BAKHTIN, 1992, p. 321, grifo do autor).

Houve, no trecho exemplificado, uma confusão acerca do destinatário. Foram dadas instruções para a elaboração do texto, e uma delas dizia respeito ao veículo de publicação: um blog; portanto, um espaço público. O texto poderia ser lido, então, por alguém que desconhece a situação na qual estão inseridos os alunos das turmas 81 e 82 do CAp-UFRGS. Configurou-se, assim, uma falha por parte da autora, pois sua concepção de destinatário previa um leitor inserido no mesmo contexto do qual ela participa.

Essa breve análise aponta que a prática pedagógica em cujas bases se desenvolve o projeto de debates no Colégio de Aplicação deve atentar à escolha do tema por duas razões:

a) como já dito, a escolha do tema é crucial para que haja engajamento dos alunos de modo que seu interesse ultrapasse a necessidade de cumprimento de tarefa; e

b) é preciso pensar-se em estratégias eficientes para se trabalhar a questão da interlocução, pois, conforme Charaudeau (2010),

[...] quando parceiros não estão presentes fisicamente um ao outro, e quando o contrato não permite a troca, o canal de transmissão pode ser oral ou gráfico. Nesse caso o locutor se encontra numa situação na qual ele não pode perceber imediatamente as reações do interlocutor (pode apenas imaginá-las). Logo, não está "à mercê" de seu interlocutor e pode organizar o que vai dizer de maneira lógica e progressiva. (CHARAUDEAU, 2010, p. 70, grifos do autor).

Entretanto, essa situação monologal dificulta ao enunciador, que ainda está em processo de autoconstrução como autor de textos argumentativos, a considerar, de forma elucidada, seu interlocutor. O eixo-temático escolhido, por sua vez, pode ser um fator contribuinte para que o estudante visualize esse interlocutor para quem escreve.

Além desse estudo, em uma análise sucinta que faço a seguir, é possível perceber como um trabalho desse tipo favorece que os alunos estabeleçam uma relação entre os conhecimentos que têm e aqueles que adquirem a serviço da construção de suas ideias.

As discussões travadas, a partir das leituras realizadas e dos vídeos assistidos durante o processo de estudo inicial e de estudo para aprofundamento, foram sempre mediadas de forma a estimular a reflexão e a pesquisa como base para a argumentação. Procurou-se levantar questionamentos acerca das informações e opiniões analisadas durante as leituras de modo que não lançassem mão de argumentos baseados no senso comum no desenvolvimento de suas produções, mas que fizessem leituras críticas, tentando identificar a intencionalidade em cada texto lido, para que elaborassem seus textos orais e escritos de forma sólida.

Conforme Britto,

[...] reconhecer a aprendizagem como mais que aquisição de padrões de comportamento e submissão aos valores do senso comum implica reconhecer que se aprende a ler e escrever ao mesmo tempo em que se aprendem os conhecimentos relevantes da história humana. (BRITTO, 2007, p. 29-30).

Em consonância com essa ideia, as atividades realizadas durante a execução do projeto visam ao desenvolvimento não da competência de produção de textos de opinião (orais e escritos) que reproduzam o já dito, mas da capacidade de refletir sobre o conhecido, de reformular o que já existe, de maneira crítica e embasada em argumentos sustentados por fatos devidamente comprovados e analisados e por reflexões aprofundadas sobre os temas estudados. 
Exemplo disso foi o argumento utilizado por uma aluna durante o debate. Sustentando a defesa da irrelevância da formatura da oitava série, a aluna citou a lei $\mathrm{n}^{\circ} 12.061$, de 2009, art. $4^{\circ}$, Inciso II, que determina a universalização do Ensino Médio gratuito, e afirmou que a universalização é a prova de que o Ensino Fundamental não encerra o ciclo escolar, mas o Ensino Médio, na forma da lei. Ao entrevistar a diretora, ela descobriu sobre a existência dessa lei, sobre a qual debruçou sua pesquisa no decorrer do processo de elaboração dos argumentos. A fala da aluna repercutiu de modo que os colegas salientaram a eficácia de sua argumentação e reconheceram a força da palavra baseada em dados confiáveis; nesse caso, reconheceram a lei como um texto consistente para embasar o posicionamento da debatedora. Ademais, ao redigirem seus textos acerca do tema previamente debatido, o que ocorreu após o debate, muitos recorreram à leitura da lei e dela se valeram durante a formulação de seu texto, ampliando seu conhecimento de mundo. Segundo Britto, “[...] o mundo da escrita não é o mundo das letras nem dos estudiosos da linguagem, é o mundo do conhecimento" (BRITTO, 2007, p. 30), o que é evidenciado por esse exemplo.

O segundo debate, cujo tema é "Os fins justificam os meios", suscitou o mesmo tipo de pesquisa. Alguns alunos leram O príncipe e pesquisaram sobre o Nazismo na Alemanha, a fim de encontrar um aporte para defender seu ponto vista sobre o tema. Desse modo, pode-se salientar a importância desse projeto como disparador de eventos de letramento, à medida que estimula alunos a pesquisarem diversos assuntos e a relacionarem suas pesquisas com conhecimentos prévios, a mudarem de opinião, a reformularem conceitos. Nas palavras de Britto,

[...] aprender a ler e escrever na escola deve, portanto, ser muito mais que saber uma norma ou desenvolver o domínio de uma tecnologia para usá-la nas situações em que ela se manifesta: aprender a ler e escrever significa dispor do conhecimento elaborado e poder usá-lo para participar e intervir na sociedade. (BRITTO, 2007, p. 30).

Há uma relação identitária evidente entre os exemplos aqui apresentados e as concepções acerca do uso da leitura e da escrita estudados em Britto (2007), ainda que tal bibliografia não tenha orientado a elaboração do projeto de pesquisa.

A segunda atividade a ser apresentada neste texto desenvolveu-se em uma disciplina eletiva chamada Shakespeare e cinema, ministrada para dez alunos de Ensino Médio, durante o primeiro semestre de 2012. Ao contrário do projeto de debates, Shakespeare e cinema teve uma duração curta, em razão de se tratar de uma disciplina de caráter semestral. Além disso, diferentemente da primeira atividade, a ideia não faz parte de um projeto de pesquisa, muito embora sua realização tenha resultado em produções que merecem estudo; dessa maneira, como não houve este enfoque durante a realização das atividades, não serão feitas considerações teóricas ao longo da descrição.

A dinâmica consistiu basicamente no estudo de três obras de Shakespeare. As obras lidas foram as tragédias Romeu e Julieta e Hamlet, e a comédia Sonho de uma noite de verão. Inicialmente, os alunos tiveram contato com o texto traduzido para a Língua Portuguesa, quando houve um processo de socialização por meio da contextualização histórico-cultural das obras, bem como com as características próprias das produções de Shakespeare. Além disso, os alunos assistiram a três produções cinematográficas baseadas nas respectivas obras. A turma teve, então, após a leitura do material de apoio e das discussões realizadas nas aulas (as quais tiveram muita participação dos alunos por meio de apresentação de seminário, leitura da obra em aula, reflexões sobre os filmes etc.), subsídios para analisar criticamente, de forma comparativa, as obras estudadas: literárias e/ou cinematográficas. Como trabalho final, cada aluno produziu um ensaio curto.

A seguir, temos um texto apresentado ao final da disciplina, em que a aluna Fernanda de Andrade Ribeiro, então estudante do primeiro ano do Ensino Médio, defendeu que não 
há amor entre Romeu e Julieta, mas simplesmente paixão, evidenciando autoria, pesquisa, reflexão, envolvimento, iniciativa e empenho para a realização da tarefa.

\section{Encantados até na morte}

As pessoas costumam relacionar enamorados com a história de amor entre Romeu e Julieta, dizendo que foi o maior caso de amor que poderia ter existido. Na obra, eles se amaram ou se apaixonaram? Essas sensações são a mesma coisa?

Amar alguém é gostar extremamente; sentir afeição; ter atração e sentimento; e ter vínculo emocional com a pessoa querendo o bem dela. Luiz Vaz de Camões descreve o amor como sendo fogo que arde sem se ver; ferida que dói e não se sente; um contentamento descontente; é dor que desatina sem doer. E para sentir isso, precisamos conhecer o amado não só fisicamente.

Paixão é uma emoção que não transmite raciocínio por ser fantasiosa à realidade. Conforme o resultado da pesquisa da professora Cindy Hazan, da Universidade Cornell de Nova Iorque, ela tem o tempo de 18 a 30 meses. Essa emoção pode ser patológica também, quando se torna um vício desejar a pessoa ou ainda quando não é correspondida além de poder ser desencadeada por circunstâncias simples como troca de olhares ou até aperto de mãos.

Segundo a célebre tragédia Romeu e Julieta que foi escrita há mais de 410 anos por William Shakespeare: Romeu Montequio encantou-se por Julieta Capuleto desde o instante em que a viu no baile de máscaras dos pais dela, em Verona. Durante o mesmo período, o bom moço conseguiu seduzir os olhos da bela senhorita desconhecida a partir das várias trocas de olhares durante a reunião. Os dois adolescentes se encontraram e se conheceram, absolvendo também seus pecados graças à união em prece de seus lábios. Os corações dos jovens beberam o mar de chocolate. Eu te amo foi a frase que brotou nos olhos de cada um dos adolescentes depois do momento em que apenas provaram os lábios peregrinos e a aparência física um do outro. Mesmo com essa bela história de final trágico, o sentimento exposto deveria ser substituído por paixão.

De acordo com o dicionário digital Caldas Aulete, a palavra desejo pode ser definida também por atração física. Ou ainda, paixão. Essa é sensação que pode ser encontrada na tragédia quando o jovem vê a moça pela primeira vez, comentando com o criado sua visão:

Ah, ela ensina as tochas a brilhar! Parece estar suspensa na face da noite, tal qual joia rara na orelha de uma etíope; beleza incalculável, cara demais para ser usada, por demais preciosa para uso terreno! Assim como se apresenta alva pomba em meio a gralhas, apresenta-se aquela dama em meio a suas amigas. Depois desta dança, verifico onde ela se posiciona, e terei sua mão sobre minha rude mão, que será assim abençoada. Meu coração amou antes de agora? Esta visão rejeita tal pensamento, pois nunca tinha visto a verdadeira beleza antes desta noite. (SHAKESPEARE. Romeu e Julieta, Ato I, Cena V, p.15).

Quando os jovens decidem se casar de repente e escondidos, transpondo a briga que há entre as famílias deles, podemos notar que é uma sensação que os fez perder a lucidez. E, com o pensamento de suicídio por possível perda do outro, podemos continuar com a hipótese inicial de paixão. Contudo, Romeu e Julieta teriam condições de se amar se não tivessem o final trágico e sem saída da morte, pois poderiam conviver mais tempo juntos e se conhecerem melhor.

Apresentadas as atividades, como se pode afirmar que estão em conformidade com as Diretrizes Curriculares Nacionais para o Ensino Médio (DCNEM) e, portanto, com a proposta do ENEM? A Resolução CNE/CEB n 2, de 30 de janeiro de 2012 - Diretrizes Curriculares Nacionais para o Ensino Médio - salienta que o Currículo do Ensino Médio deve “[...] garantir ações que promovam a educação tecnológica básica, a compreensão 
da ciência, das letras e das artes, a adoção de metodologias de ensino e de avaliação de aprendizagem que estimulem a iniciativa dos estudantes" (2012, p. 4). As atividades apresentadas, além de promoverem o que descreve a Resolução, estimulam a autonomia à medida que, para sua realização, requer-se pesquisa, bem como colaboração com o grupo e compartilhamento de conhecimentos.

Conforme Moehlecke,

[...] o termo "flexibilização", fortemente criticado nas DCNEM de 1998, é agora substituído pela expressão "diversidade". Este termo é usado no parecer das DCNEM de 2011 com múltiplos significados: em alguns momentos, refere-se às políticas de diferença e identidade cultural; em outros, à variedade de interesses dos jovens de modo geral; e em várias ocasiões, aparece também como sinônimo de flexibilização. (MOEHLECKE, 2012, p. 55).

Nesse sentido, reitera-se um dos objetivos dessas práticas, salientado no início do texto: manter os alunos interessados em aprender. A autora ressalta um dos significados da expressão "diversidade” como referência à variedade de interesses dos jovens de modo geral. Quem trabalha com adolescentes conhece as dificuldades para mantê-los envolvidos nas dinâmicas, haja vista os inúmeros atrativos eletrônicos a eles disponíveis. Uma atividade extracurricular faz a escola mais interessante para o aluno, possibilitando que ele torne seus conhecimentos mais concretos por meio da sua aplicação em diferentes contextos.

\section{Considerações finais}

As práticas realizadas em sala de aula no ano de 2012, anteriormente descritas e analisadas, evidenciam que sair da sala de aula, utilizar diferentes recursos de pesquisa, discutir com o grupo, estabelecer relações com conhecimentos prévios e, principalmente, variar atividades, criando possibilidades que ultrapassam o currículo regular são recursos que corroboram com o sucesso de atividades que envolvem adolescentes e, consequentemente, com a caminhada a ser percorrida a fim de alcançar os três objetivos salientados como norte do trabalho aqui apresentado.

\section{Referências}

BAKHTIN, Mikhail. Estética da criação verbal. São Paulo: Martins Fontes, 1997.

BRITTO, Luiz Percival Leme. Escola, ensino de língua, letramento e conhecimento. Calidoscópio. São Leopoldo: Unisinos, v. 5, n.1, jan./mar. 2007.

CHARAUDEAU, Patrick. Linguagem e discurso - modos de organização. São Paulo: Contexto, 2010.

GUEDES, Paulo Coimbra. A formação do professor de português. Que língua vamos ensinar? São Paulo: Parábola, 2006.

MOEHLECKE, Sabrina. O ensino médio e as novas diretrizes curriculares nacionais: entre recorrências e novas inquietações. Universidade do Rio de Janeiro. Disponível em http://www.scielo.br/ pdf/rbedu/v17n49/a02v17n49.pdf. Acesso em: 07 mar. 2013.

PCN - Parâmetros curriculares nacionais - Língua portuguesa. Secretaria de Educação Fundamental. Brasília: MEC/SEF, 1997.

PNLD 2011 - Guia de livros didáticos - Língua Portuguesa - Anos finais do Ensino Fundamental. Secretaria de Educação Básica. Brasília: MEC/SEB, 2010.

RIBEIRO, Roziane Marinho. A Construção da argumentação oral no contexto de ensino. São Paulo: Cortez, 2009. 